Surgical treatment of orbital tumors at a single institution". J Korean Neurosurg Soc, 44, 146- 150.

6. Abuzayed B, Kucukyuruk B, Tanriover N, Sanus GZ, Canbaz B, Akar Z, et al. (2012), "Transcranial superior orbitotomy for the treatment of intraorbital intraconal tumors: surgical technique and long-term results in single institute". Neurosurg Rev, 35(4), 573-582.

7. Markowski J, Jagosz-Kandziora E, Likus W, Pajak J, MrukwaKominek E, Paluch J, et al.
(2014), "Primary orbital tumors: a review of 122 cases during a 23-year period: a histo-clinical study in material from the ENT Department of the Medical University of Silesia". Med Sci Monit, 20, 988-994.

8. Boari N, Gagliardi F, Castellazzi P, Mortini P (2011), "Surgical treatment of orbital cavernomas: clinical and functional outcome in a series of 20 patients". Acta Neurochir (Wien), $153(3), 491-498$

\title{
KẾT HỢP NÚT TĨNH MACH CỬA VÀ TĨNH MACH GAN LÀM PHÌ ĐẠI GAN TRƯỚC PHẪU THUÂTT CẮT GAN LỚN: BÁO CÁO TRƯờNG HỢP
}

\author{
Lê Thanh Dũng ${ }^{1}$, Thân Văn Sỹ ${ }^{1}$, Ninh Viết Khải \\ Đào Xuân Hải ${ }^{1}$, Nguyễn Quang Nghĩa ${ }^{2}$
}

\section{TÓM TẮT}

Nút mạch đồng thời tĩnh mạch cửa và tĩnh mạch gan (LVD) được áp dụng rộng rãi trong thời gian gần đây do làm tắng đáng kể tốc độ và mức độ phì đại gan trước phấu thuât cắt gan lớn so với phướng pháp nút tĩnh mạch cửa (PVE) đơnn thuần, từ đó rút ngắn được thời gian chờ đợi phẫu thuật và giảm nguy cơ khổi u tiến triển. Chúng tôi báo cáo một trượng hợp được thực hiện LVD làm phì đại gan trước phẫu thuật cắt gan lớn do khối ung thư đường mật trong gan. Sau thủ thuật, bệnh nhân có tăng đáng kể thể tích gan còn lại theo dự kiến trong vòng 3 tuần. Phẫu thuật cắt gan phải mở rộng sau thời điểm nút mạch 4 tuần mà không có biến chứng suy gan sau phẫu thuât. Qua trường hợp lâm sàng này, chúng tôi nhận thấy LVD có hiệu quả cao trong việc làm tăng thể tích gan còn lại theo dự kiến (FLR) trước phẫu thuật cắt gan lớn.

Tư khoá: Nút tĩnh mạch cửa, nút tĩnh mạch gan, phẫu thuật cắt gan lớn, ung thư đường mật.

\section{SUMMARY}

SIMULTANEOUS PORTAL AND HEPATIC

\section{VEIN EMBOLIZATION BEFORE MAJOR}

LIVER RESECTION: A CASE REPORT

Simultaneous portal hepatic vein embolization (LVD) has been widely applied in recent years because of significantly increasing the rate and degree of liver hypertrophy in comparison with portal venous embolization (PVE) before major hepatectomy. So that, LVD brings the shortening waiting time for surgery and reducing the risk of tumor progression. We report a case where LVD was performed before major hepatectomy due to intrahepatic cholangiocarcinoma. The patient then had a significant

\footnotetext{
${ }^{1}$ Bệnh viện Hữu nghi Việt Đức

${ }^{2}$ Trung tâm Ghép Tạng - Bệnh viện Hữu nghị Việt Đức Chiu trách nhiệm chính: Thân Văn Sỹ

Email: sy.hmu0915@gmail.com

Ngày nhận bài: 10.8.2021

Ngày phản biện khoa học: 5.10 .2021

Ngày duyệt bài: 14.10.2021
}

increase in the future liver remnant (FLR) after 3 weeks. Major liver resection then was performed at 4 weeks after LVD without postoperative liver failure. From this clinical case, we found that LVD was highly effective in increasing FLR before major hepatectomy. This procedure could be a great alternative to PVE, especially in case of small initial FLR.

Keywords: Portal vein embolization, hepatic vein embolization, major liver resection, cholangiocarcinoma.

\section{I. ĐĂT VẤN ĐỀ}

Phẫu thuât cắt gan cho tới nay vẫn là phương pháp điều trị chính đối với các tổn thương ác tính tại gan. Nhược điểm chính của phương pháp này là nguy cơ suy gan sau phẫu thuật, đặc biệt ở những trường hợp cân cắt gan lớn mà thể tích gan không đủ [1]. Nút tĩnh mạch cửa (portal venous embolization - PVE) gây phì đại gan là kỹ thuật đã được áp dụng trên toàn thế giới từ nhiểu năm nay, góp phân mở rông chỉ định cắt gan và cải thiện kết quả sau phẫu thuâtt [2]. Mắc dù vậy, thủ thuật này đòi hỏi thời gian chờ đợi tương đối dài, thường phải sau 6 - 8 tuân. Hơn nữa, theo các báo cáo, có tới 30\% trường hợp bênh nhân sau PVE không thể phẫu thuât vì tăng thể tích gan còn lại theo dự kiến (future liver remnant - FLR) không đủ hoăc do khối u tiến triển [2].

Gần đây, trên thế giới đã và đang áp dụng phương pháp nút đồng thời tĩnh mạch cửa và tĩnh mạch gan (liver venous deprivation - LVD) thay thế cho PVE, cho thấy an toàn và tăng hiêu quả đáng kể về khả năng phì đai gan so với PVE [3], [4], [5]. Chúng tôi trình bày trường hợp lâm sàng được thực hiện nút đồng thời tĩnh mạch cửa và tĩnh mach gan nhằm mục đích gây phì đại gan trước phẩu thuât cắt gan lớn cùng một số tổng kết từ y văn. 


\section{PHƯƠNG PHÁP NGHIÊN CỨU}

Phương pháp mô tả ca lâm sàng tại Bênh viện Hữu nghị Việt Đức tháng 6 năm 2020, và tổng kết y văn về áp dụng LVD để làm phì đại gan trước phẫu thuật cắt gan lớn.

\section{CA LÂM SÀNG}

Bệnh nhân nam 57 tuổi, tiền sử viêm gan $B$ mạn tính. Siêu âm phát hiện đám tổn thương giảm âm gan phải kích thước $55 \mathrm{~mm}$ khi đi kiểm tra sức khoẻ định kỳ. Cắt lớp vi tính ngực - bụng - tiểu khung được chỉ định, cho thấy khối tổn thương kích thước $55 \times 61 \mathrm{~mm}$, nằm ở hạ phân thuỳ VII-VIII, xâm lấn tĩnh mạch gan giữa và lan một phần sang hạ phân thuỳ IV (Hình 1). Tổn thương ngấm thuốc kém thì động mạch, tĩnh mạch, ngấm nhiều hơn ở thì muộn. Bờ của tổn thương không đều, ranh giới không rõ, kèm co kéo bao gan lân cận. Ngoài ra còn một số nốt vệ tinh nhỏ nằm rải rác trong HPT VII-VIII. Các đặc điểm này phù hợp với hình ảnh của ung thư đường mật trong gan. Xét nghiệm máu cho thấy alphaFP $5,5 \mathrm{ng} / \mathrm{ml}$, CEA $1,7 \mathrm{ng} / \mathrm{ml}$, CA $19-978$ UI/L, AST 31U/L, ALT 25U/L, Bilirubin toàn phần 31.4 umol/l, bilirubin trực tiếp 7.3 umol/l, tiểu cầu 147, prothrombin $87 \%$. Kết quả sinh thiết khối u gan khẳng định ung thư đường mật trong gan. Bệnh nhân được chỉ định phẩu thuật cắt gan phải mở rộng (lấy bỏ toàn bộ gan phải và HPT IV), tuy nhiên thể tích gan HPT I+II+III, phần còn lại dự kiến (Future liver remnant - FLR), là $397 \mathrm{ml}$, chiếm < 0,5\% tổng trọng lượng cơ thể, không đảm bảo duy trì chức nằng gan sau phẫu thuật. Sau khi hội chẩn đa chuyên khoa, thủ thuật nút tĩnh mạch cửa kết hợp nút tĩnh mạch gan được thực hiện nhằm mục đích tăng FLR và rút ngắn thời gian chờ đợi phẫu thuật nhất có thể. Tĩnh mạch cửa phải được nút tắc bằng 01 Amplatzer vascular Plug I $8 \times 14 \mathrm{~mm}$ và hỗn hợp của NBCA và Lipiodol (tỷ lệ 1:4). Tĩnh mạch gan phải tiếp đó được nút tắc bởi 01 Amplatzer Vascular Plug II $18 \times 20 \mathrm{~mm}$. Sau thủ thuật bênh nhân ổn định, không có bất kỳ biến chứng đáng kể nào liên quan đến thủ thuật. Cắt lớp vi tính ổ bụng được thực hiện sau đó 3 tuần cho thấy khối u đường mật ổn định, thể tích gan phân thuỳ bên (HPT I+II+III) đo được $608 \mathrm{ml}$ (Hình 2). Với FLR tăng lên đáng kể sau phẫu nút mạch (chiếm 0,8\% tổng trọng lượng cơ thể), phẫu thuật cắt gan phải mở rộng (bao gồm toàn bộ gan phải và một phần HPT IV) được thực hiện sau đó 1 tuần. Sau phẫu thuật, không có tình trạng suy gan trên lâm sàng và xét nghiệm, cũng như bất kỳ biến chứng đáng kể nào khác được nghi nhận. Bệnh nhân hồi phục tốt và được xuất viện sau 15 ngày.

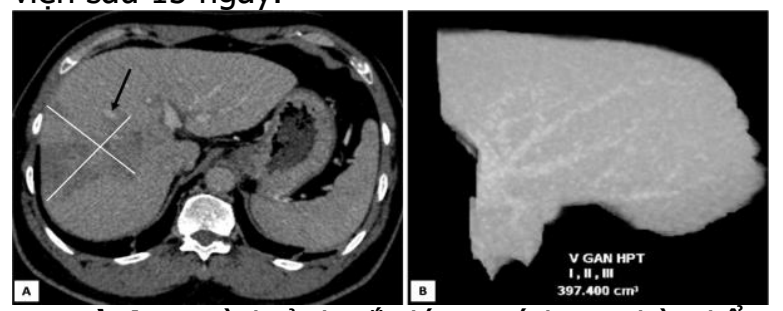

Hinh 1: Hình ảnh cắt lớp vi tính tại thời điểm trước nút mạch. Khối u gan ngấm thuốc kém nằm ở hạ phân thuỳ VII-VII, xâm lấn tĩnh mạch gan giữa (mũi tên đen) và một phần hạ phân thuỳ IV $(A)$. Thể tích gan còn lại dự kiến gồm hạ phân thuỳ I+II+III đo được 397ml.

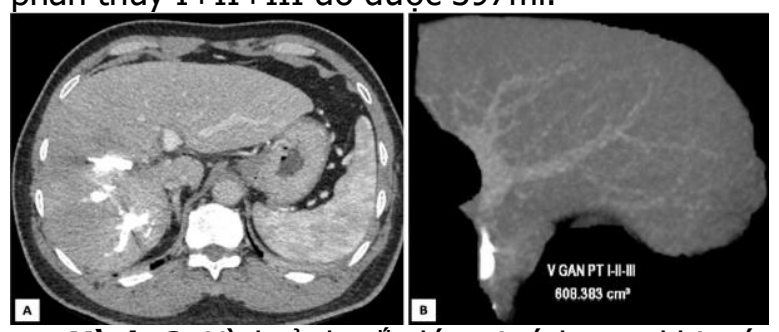

Hình 2: Hình ảnh cắt lớp vi tính sau khi nút tĩnh mạch cửa và tĩnh mạch gan 3 tuần. Gan thay đổi hình thái: giảm thể tích gan phải, tăng thể tích gan trái $(A)$. Thể tích gan còn lại dự kiến gồm hạ phân thuỳ I+II+III đo được 608 ml.

\section{BÀN LUẬN}

Ung thư đường mật là bệnh lý ác tính nguyên phát phổ biến thứ 2 tại gan sau ung thư tế bào gan nguyên phát. Cho tới nay, mặc dù nhiều phương pháp điều trị mới cùng với các thế hệ thuốc chống ung thư mới ra đời, phẫu thuật vẫn là phương pháp điều trị chính và có hiệu quả nhất đối với ung thư đường mật trong gan. Trường hợp bệnh nhân của chúng tôi, khối ung thư đường mật gan phải với kích thước lớn và lan sang tới cả HPT IV. Do FLR còn lại quá nhỏ không thể tiến hành phẫu thuật ngay, thủ thuật nút tînh mạch gây phì đại gan trước phẫu thuật là cần thiết để tránh biến chứng suy gan sau mổ.

Với mục đích làm phì đại gan trước phẫu thuật, phương pháp nút đồng thời tĩnh mạch cửa và tĩnh mạch gan được áp dụng trong những năm gần đây để thay thế cho nút tĩnh mạch cửa đơn thuần do có độ an toàn tương đương trong khi có mức độ phì đại gan nhiều hơn và thời gian chờ đợi phẫu thuật ngắn hơn. Le Roy và cộng sự so sánh 31 bệnh nhân được thực hiện kỹ thuật nút tĩnh mạch kép và 41 bệnh nhân được nút PVE đơn thuần, không có biến chứng nặng liên quan đến quá trình can thiệp. Nhiều nghiên cứu 
khác cũng cho kết quả tương tự [5], [6]. Cũng phải nhắc lại rằng, cho tới nay, nhiêu phương pháp gây phì đại gan đã được áp dụng ( $P V E$, PVE kết hợp nút động mạch gan, LVD, phẫu thuật thắt tĩnh mạch cửa phải kết hợp phân tách nhu mô gan hai thuỳ và cắt gan thì hai (ALPPS)...) tuỳ thuộc vào mức độ phì đại gan cần thiết, tình trạng của nhu mô gan cũng như chiến lược phẫu thuật của từng trường hợp cụ thể [7], [8]. Chung quy lại, các thủ thuật can thiệp điện quang (PVE và LVD) ít xâm lấn hơn mặc dù có hiệu quả phì đại gan thấp hơn so với các can thiệp ngoại khoa (ALPPS). ALPPS được báo cáo lần đầu năm 2011, cho thấy có tốc độ phì đại FLR rất nhanh chóng (74\% trong 9 ngày) [7]. Tuy nhiên, tỷ lệ các biến chứng lớn còn ở mức cao và tỷ lệ tử vong lên đến $12 \%$ [7]. Do đó, LVD đã và đang được áp dụng ngày càng rộng rãi hơn [3].

Trường hợp lâm sàng của chúng tôi cho thấy, FRL sau 3 tuần tăng $53,1 \%$ so với trước can thiệp $(608 \mathrm{ml}$ so với $397 \mathrm{ml})$. Kết quả này khá tương đồng với kết quả của các nghiên cứu khác [3]. Trong nghiên cứu của Le Roy B. và cộng sự thực hiện trên 72 bệnh nhân cho thây tỷ lệ tăng FLR sau 3 tuần lần lượt là $51,2 \%$ và $31,9 \%(p=$ 0,018 ) của nhóm LVD và PVE [6]. Tương tự, nghiên cứu của Laurent $C$. và cộng sự cũng cho thấy tỷ lệ phì đại FLR sau 4 tuần của nhóm LVD và PVE lần lượt là $61.18 \%$ và $28.98 \%$ [6]. Cơ chế liên quan đến sự tăng mức độ phì đại gan sau LVD so với PVE có lẽ do sự tăng áp lực tĩnh mach cửa của vùng gan dự kiến không cắt bỏ. Nút tắc tĩnh mạch cửa làm giảm đáng kể lưu lượng dòng máu tại thuỳ gian dự kiến cắt bỏ và làm tăng lưu lượng máu tại thuỳ gan bên đối diện [8]. Điều này dẫn đến giải phóng các chất kích thích tân taao gan ở thùy gan không nút mạch. Cơ chế này được biết đến là "phản ứng đệm động mạch gan" (hepatic arterial buffer response), gây phì đại gan qua cơ chế thiếu oxy [8].

Rõ ràng là thời gian chờ đợi sau nút mạch và mức độ phì đại gan ảnh hưởng rất lớn đển khả năng phâu thuật của bệnh nhân. Theo các báo cáo trước đây, phương pháp PVE thường có thời gian chờ đợi dài, khoảng 6-8 tuần cho tới khi đủ tăng đủ FLR. Trong khi đó, có đến 30 - 35\% số bênh nhân sau PVE không thể tiến hành phẫu thuật do tăng thể tích gan không đủ hoặc do khối u tiến triển [9]. Trong nghiên cứu của Kobayashi $K$. và cộng sự, tỷ lẹ bệnh nhân được phẫu thuât ở nhóm PVE và LVD lần lượt là $76,9 \%$ và $95,2 \%$ [4]. Le Roy $B$. và cộng sự báo cáo tỷ lệ phẫu thuật là $76 \%$ và $81 \%$ ở nhóm PVE và LVD [3]. Như vậy các nghiên cứu đều cho thấy LVD giúp làm tăng tỷ lệ phầu thuật so với PVE.

Khi so sánh về độ an toàn giữa $L V D$ và $P V E$, các nghiên cứu gần đây đều cho thây LVD có tỷ lệ biến chứng và tử vong không khác biệt so với PVE [3], [4].

Đây là trường hợp đầu tiên chúng tôi áp dụng kỹ thuật LVD thay thế cho PVE trong việc gây phì đại gan trước phẩu thuật cắt gan lớn cho thấy kỹ thuật này có thể thực hiện tại Việt Nam, với ưu việt về mức độ cũng như tốc độ phì đại gan so với PVE. Những nghiên cứu với số lượng lớn hơn, có so sánh ngẫu nhiên cần được thực hiện đế đánh giá chính xác độ an toàn và hiệu quả của phương pháp này.

\section{KẾT LUÂN}

Qua trường hợp lâm sàng này chúng tôi nhận thấy LVD là thủ thuật an toàn và hoàn toàn có thể thực hiện được tại Việt Nam. LVD kỳ vọng mang lại hiệu quả cao trong việc gây phì đại gan trước khi cắt gan lớn, có lẽ sẽ là một lựa chọn thay thế ưu việt hơn so với kỹ thuật PVE truyền thống.

\section{TÀI LIÊU THAM KHẢO}

1. Rahbari N.N., Garden O.J., Padbury R. và công sứ. (2011). Posthepatectomy liver failure: a definition and grading by the International Study Group of Liver Surgery (ISGLS). Surgery, 149(5), 713-724.

2. Van Lienden K.P., Van Den Esschert J.W., De Graaf W. và cộng sự. (2013). Portal vein embolization before liver resection: a systematic review. Cardiovascular and interventional radiology, 36(1), 25-34.

3. Le Roy B., Gallon A., Cauchy F. và cộng sự. (2020). Combined biembolization induces higher hypertrophy than portal vein embolization before major liver resection. HPB, 22(2), 298-305.

4. Kobayashi K., Yamaguchi T., Denys A. và cộng sứ. (2020). Liver venous deprivation compared to portal vein embolization to induce hypertrophy of the future liver remnant before major hepatectomy: A single center experience. Surgery, 167(6), 917-923.

5. Guiu B., Quenet F., Escal L. và cộng sự. (2017). Extended liver venous deprivation before major hepatectomy induces marked and very rapid increase in future liver remnant function. European radiology, 27(8), 3343-3352.

6. Laurent C., Fernandez B., Marichez A. và cộng sự. (2020). Radiological simultaneous portohepatic vein embolization (RASPE) before major hepatectomy: a better way to optimize liver hypertrophy compared to portal vein embolization. Annals of Surgery, 272(2), 199-205.

7. Schnitzbauer A.A., Lang S.A., Goessmann H. và công sứ. (2012). Right portal vein ligation combined with in situ splitting induces rapid left lateral liver lobe hypertrophy enabling 2-staged 
extended right hepatic resection in small-for-size settings. Annals of surgery, 255(3), 405-414.

8. Le Roy B., Dupré A., Gallon A. và công sự. (2018). Liver hypertrophy: Underlying mechanisms and promoting procedures before major hepatectomy. Journal of visceral surgery, 155(5), 393-401.

9. Lê Thanh Dũng (2018), Nghiên cứu áp dụng và đánh giá hiệu quả của phương pháp nút nhánh tĩnh mạch cửa gây phì đại gan trước phẩu thuật cắt gan, Luận án Tiến sĩ Y học, Đại học Y Hà Nội.

\section{ĐÁNH GIÁ Độ CHÍNH XÁC VÀ AN TOÀN CỦA KỸ THUÂT TIÊM NGOÀI MÀNG CỨNG CộT SỐNG THẮT LƯNG DƯỚI HƯỚNG DẪN CỦA SIÊU ÂM}

\section{TÓM TẮT}

Mục tiêu: bước đầu đánh giá độ chính xác và an toàn của phương pháp tiêm steroid ngoài màng cứng qua lỗ liên hợp bằng cách xác thực dưới $x$ quang. Phương pháp: nghiên cứu mô tả 15 người bênh, đau kiểu rễ thần kinh do thoát vị đĩa đệm cột sống thắt lưng, được tiến hành tiêm steroid ngoài màng cứng qua lỗ liển hợp với kim được dẫn đường dưới hướng dẫn của siêu âm trên bình diện cắt ngang của cột sống và được xác thực bằng chụp x quang. Kết quả: độ chính xác của can thiệp dưới hướng dân của siêu âm là 86,7\% được xác thực bởi chụp x quang. Có 02 trường hợp không chính xác: 01trường hợp sai tâng và 01 trường hợp đúng tầng nhưng kim ở ngoài lố liên hợp. Không có biến chứng nào được ghi nhận. Kết luận: Tiêm ngoài màng cứng qua lố liên hợp là chính xác và có thế thực hiện trong lâm sàng với độ chính xác bước đâuu là $86,7 \%$ và không có biến chứng.

Tư khóa: Tiêm ngoài màng cứng, đau thắt lưng, đau kiểu rễ thần kinh, thoát vị đĩa đệm, siêu âm

\section{SUMMARY}

\section{THE ACCURACY AND SAFETY OF ULTRASOUND - GUIDED LUMBAR TRANSFORAMINAL EPIDURAL INJECTION}

Objective: To investigate the accuracy and safety rate (technical precision) of ultrasound-guided lumbar transforaminal epidural steroid injection, which was validated by conventional fluoroscopic technique. Methods: A total of 15 patients with unilateral singlelevel lumbar foraminal disc protrusion causing radiculopathy were enrolled. Using transforming route, the needle location was determined by an axial (transvers) view of the ultrasound with fluoroscopic confirmation. Results: The accuracy of ultrasoundguided interventions was $86,7 \%$ as confirmed by fluoroscopy. There were 02 failed cases in the USguided: 01 case were wrong level and 01 case was right level but in extraforaminal. No complications

*Bệnh viện HN Việt Đức

Chịu trách nhiệm chính: Nguyễn Hoàng Long

Email: longnguyen.drspine@gmail.com

Ngày nhận bài: 5.8.2021

Ngày phản biên khoa họ: 5.10 .2021

Ngày duyệt bài: 14.10.2021

\section{Nguyễn Hoàng Long*, Vũ Văn CườngB*, Nguyễn Duy Linh*, Lê Đức Anh*}

were noted. Conclusion: Ultrasound-guided lumbar transforaminal epidural injections are accurate and feasible in clinical setting with an accuracy of $86,7 \%$ and no complications.

Key word: Epidural injection, low back pain, radiculopathy, disc herniation, ultrasound

\section{I. ĐẶT VẤN ĐỀ}

Đau kiểu rễ thần kinh cột sống thắt lưng thường do nguyên nhân chèn ép hoặc kích thích các rễ thân kinh tương ứng trong ống sông hoặc trên đường đi của rễ. Các phương pháp điêuu trị từ bảo tôn cho tới phẫu thuật.Phong bế ngoài màng cứng (NMC) qua lỗ liên hợp là thủ thuật hay được dùng điều trị đau lan kiểu rễ thân kinh do nguyên nhân từ cột sống[1]. Thông thường thủ thuật này sẽ được thực hiện dưới hướng dẫn của X-quang hoặc cắt lớp vi tính vì có thể quan sát đâu mũi kim và sự lan thuốc cản quang. Tuy nhiên, nhược điểm chính của thủ thuật này là nguy cơ nhiễm tia chongười bệnh(NB), bác sĩ và các nhân viên y tế khác, yêu cầu có khu vực đặc biệt (buông có bọc chì, tấm chắn tia $X$, bàn làm thủ thuật cần thấu quang...) để thực hiện những thủ thuật này, trang thiết bị đắt tiền, mặc đồ bảo hộ nặng, nóng và không thoải mái.Trong vài năm gần đây, tiêm phong bế thần kinh dưới hướng dẫn của siêu âm được áp dụng cho thấyđã khắc phục được những nhược điểm nói trên của phương pháp phong bế dưới hướng dẫn của $x$ quang và cắt lớp vi tính. Mặc dù siêu âm được chứng minh là an toàn và khả thi đối với tiêm cột sống như tiêm phong bế rễ thân kinh, phong bế nhánh trong, và tiêm diện khớp, nhưng đối với phương pháp tiêm NMC qua lỗ liên hợp vẫn còn những thách thức vì bóng cản của các cấu trúc xương ở khu vực lỗ liên hợpvì vậy gây khó khăn cho sự quan sát đâu kim ở vị trí này.

Ở Việt Nam, phương pháp tiêm NMC qua lỗ liên hợp dưới hướng dấn của $X$ quang đã được tiến hành ở một số trung tâm như bệnh viện HN Việt Đức, bệnh viện trung ương Đà Nẵng ... Còn 